\title{
反对現代俈正主义 研究当代革命問題
}

\section{中国科学院哲学社会科学部委員会擴大会議討論学術战线的任务}

中国科学院哲学社会科学部委員会最近在北京举行了第四次扩大会議, 討論在目前 国內外形势下哲学社会科学战綫的任务。

出席会議的, 除了中国科学院哲学社会科学部的学部委員以外, 还有一部分著名学 者和青年研究人員。中共各中央局和各省、市、自治区党委宣传部, 哲学社会科学各研 究机构和其他有关机关的負責人也参加了这次会議。

刘少奇主席向会議作了重要䛍話。

国务院副总理薄一波在会上作了当前我国經济形势和任务的报告。

会議由中国科学院院长郭沫若主持。中共中央宣传部副部长周揚在会上作了題为 “哲学社会科学工作者的战斗任务”的报告。中国科学院哲学社会科学部副主任潘梓年作 了学部工作报告。

会議着重討論了在哲学社会科学战綫积极开展反对現代修正圭义的斗爭、重新学习 馬克思列宁主义、学习毛泽东思想的問題, 加强对当代革命斗爭經驗的研究的問題, 以 及培养和鍛炼哲学社会科学队伍的問題。

会議指出，当前国际共产主义运动中革命馬克思列宁主义同現代修正主义之間正在 进行一場有伟大历史意义的大論战。哲学社会科学工作者必須参加到这个斗爭中去, 发 揮积极的作用，作出应有的貢献。現代修正主义全面地篡改了馬克思列宁主义的革命路 綫和理論基础。他們在哲学、政治經济学、社会主义和共产主义学說、历史学、文艺理 論等各个方面，向着馬克思主义的基本原理进攻。我們必須从政治上、理論上, 从哲学 社会科学的各个領域，对現代修正主义进行全面的、系統的批制，保卫、宣传和发展馬 克思列宁主义。这是当前哲学社会科学战綫的头等重要的任务。

会議指出，哲学社会科学工作者只有积极参加这个斗爭，才能把自己鍛炼成为好的 革命者, 战斗的馬克思主义者。在斗孚的紅炉中，一些原来还不是革命者的人可能变成 为革命者, 原来还不是馬克思主义者的人可能变成为馬克思主义者。这样，社会科学的 学术水平就能够提高, 馬克思主义理論水平就能够提高。馬克思主义是需要在斗爭中发 展的。現在世界人民革命的規模已經极大地扩大了, 新的革命經驗正在大量地积累起 来。在反对現代修正声义的斗爭中, 正确总結这些經驗, 使之成为系統的理論, 就能发 展馬克思列宁主义。

許多同志在会上发言，对現代修正主义在哲学、社会科学各方面的表現，进行了揭 露和批制。 
发言的同志着重指出，現代修正主义者用帝国主义时代餈产阶級唯心主义的实用主 义哲学代替无产阶級的讋証唯物主义, 抛弃了馬克思主义的唯物主义，也抛弃了革命的 辯証法。他們歪曲和修改馬克思列宁主义关于矛盾規律的学説, 宣传調和矛盾; 融合矛 盾的理諭，为他們的“和平共处”、“和本竞賽”、“和平过渡”和“全民国家”、“全民党”的 政治路綫制造理論根据。現代修正主义者把人道主义的概念和科学共产主义的概念相提 并諭而且等同起来，宣传什么“共产主义是人道全义的最高体現”、“人道主义是馬克思 列宁圭义的核心”，企图把馬克思列宁主义、共产主义完全融合于資产阶級的人道主义 之中。这实际上是用資产阶級的人道主义，代替无产阶級的共产主义，用抽象的、超阶 級的人性論, 反对馬克思列宁声义的阶級斗学学説, 反对无产阶級革命和无产阶 級专 政。他們装腔作势, 口声声反对意識形态的和平共处, 实际上正是企图通过資产阶級 人道吉义这座桥梁，把无产阶級意識形态同資产阶級意識形态調和融合起来。

在政治經济学方面, 他們宣称列宁主义关于帝国主义的原理已經过时; 片面地、不 适当地宣揚所謂个人物稹刺激的原則, 而且企图用一些資本主义經济的原則代替社会主 义經济的原則，为社会主义經济逐步向資本主义經济蛻化开辟道路。在社会主义、共产 主义学說方面, 他們根本篡改了馬克思列宁圭义关于国家、关于无产阶級专政、关于无 产阶級政党的学說, 在还存在阶級斗学和阶級差別的条件下, 宣布 “无产阶級专政已經 不再是必要的了”，已經变成什么“全民国家”、“全民民主”了，无产阶級政党也变为什 么“全民党”了，粒且把这种謬論説成是一种“新发明”。

会議討論了今后哲学社会科学研究工作的重点, 訩为必須䢔循理諭和实际相結合的 原則，結合当前反对現代修正主义的斗爭，运用馬克思列宁主义的立場、覌点和方法来 研究我国革命和建設的經驗和問題, 研究世界人民革命的經驗和問題, 研究我国和世界 的历史，而把研究現代革命斗争的經驗抾到整个社会科学研究工作的首位。我国的民主 革命、社会主义革命和社会㐊义建設的經驗是极为丰富的。对于这些經驗，毛泽东同志 和我党中央已經从根本上作出了概括。社会科学工作者应当以馬克思列宁主义、毛泽东 思想为指导，把这些經驗分門別类地从学术上加以研究和閣述，对实践中得出的各种問 題, 进行研究, 写成革命的科学的著作, 用来指导实践, 教育后代, 并且对世界革命人 民作出我們的国际主义貢献。同时，还要加強对世界各国的研究，加強对世界各国人 民, 特別是亚洲、非洲、拉丁美洲各国人民革命斗爭經驗的研究, 加強对国际斗爭中出 現的新問題的研究。为此, 必須适当扩充和加強研究外国的专門机构和高等学校中有关 这一方面的专业。

会議指出，我們的研究工作必須面向現实，厚古薄今的思想是不对的。我們应当勇 敢地去探索前人所未曾探索过的問題。我們革命的社会科学工作者, 要䚯識世界, 改造 世界, 就要对許多問題进行新的探索。在探索过程中, 遇到这样那样的困难, 发生这样 那样的錯誤，是难以避免的。只有披荆斬棘、不畏险阻的人，只有不怕犯錯誤，而又勇 于改正錯誤，不断改造自己的人，才能在科学上作出真正的貢献。

会議䚿为, 在历史研究中, 应当注重近代史現代史的研究。对于我国和外国的学术 文化遺产, 应当用馬克思列宁圭义的覌点进行研究, 給以批制的总結。如何对待历史遺 
产的問題，实际上是涉及意識形态領域无产阶級思想和資产阶級思想、封建吉义思想的 斗爭的問題, 是历史唯物主义和历史唯心主义两种不同历史覌的斗学的問題, 是在历史 科学的領域內要不要树立馬克思主义批判旗帜的問題。一切历史遺产，只有用馬克思主 义的历史圭义的阶級分析的方法加以分析制断，才能区別其中的精华和糟粕，决定去存 取舍。遺产中的精华，也只有經过馬克思主义的批制，才能成为科学的东西，才能成为 对于我們今天有意义的东西。我們必須鼓励那些敢于跳出前人的窼臼，用馬克思主义覌 点去重新評价历史、研究历史經驗，提出新命題、新覌点的人，鼓励他們的理論勇气。 同时，把高度的革命性和高度的科学性統一起来，力戒簡单化的毛病。

会議訩为，在社会科学工作中，无論研究現实閶題、理論問題，或者研究历史遗 产，都要継續坚持在馬克思列宁主义的指导下，实行百家爭鳴的方針。离开了馬克思主 义的方向，百家爭鳴就会变成現代修正主义所希望、所实行的自由化的方針。反之，如 果在学术問題上不实行百家争鳴的方針，不鼓励自由討論，不鼓励独立思考，而采用行 政命令的办法去解决复杂的精神世界的問題，那末，学术界的思想就会陷于俉化。一方 面反对和防止資产阶級自由化，另一方面又反对和防止思想偎化，这是在学术思想領域 內必須进行的两条战綫的斗拿。

会議䚯为, 必須适应当前斗爭形势的需要, 大大加強哲学社会科学的队伍。应当有 更多的青年投入这条战綫，扩大这条战綫。科学研究机构、高等学校和有关实际工作部 門都应当䚯真注意这一方面的工作，各地研究机构应当特別注意在当地发現和培养人 才。会議䚯为，在培养社会科学队伍的問題上，存在着两条根本不同的路綫。一条是: 按照无产阶級的方向, 郎全心全意为人民服务的又紅又专的方向来培养, 使社会科学工 作者成为和劳动人民密切結合的无产阶級的战士; 另一条是：按照資产阶級的方向，郎 追求个人名利, 只专不紅的方向来培养, 使他們成为和劳动人民脫离, 高踞于劳动人民 之上的精神貴族。采取后一条路綫，就只能培养出修正主义者，培养出新的反动的資产 阶級专家。大家訩为, 毛泽东同志提出的文学艺术工作者必須到工农莘众中去, 到实际 的斗爭中去的原則, 对社会科学工作者也是同样适用, 同样需要, 同样是一个根本性的 問題。社会科学工作者一方面要訩真讀书, 系統地积累賀料, 掌握丰富的知識; 另一方 面又必須积极参加工农掱众的劳动和斗爭，取得基层工作的鍛炼，改造自己，真正做到

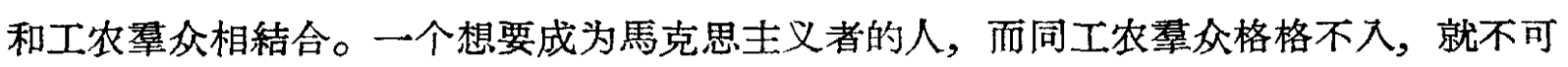
能成为真正的馬克思圭义者。

在討諭中，許多同志表示，我們处在伟大的社会主义的时代，我們不应当辜負时代 和人民的期待，而应当发憤努力，在科学研究的各个領域內創造出輝煌的成果。

在会上发言的有尅玉章、林默涵、宦 乡、艾思奇、襲育之、李宝恒、关 鋒、 林聿时、馮友兰、賀 暽、张世英、王亚南、王紹飞、于光远、姚 耐、孙治方、 邓 拓、黎 澍、朱光潛、叶水夫、叶以㖕、姚文元、毛 星等同志。

自然科学家錢学森在会上作了关于現代自然科学和工程技术发展的报告。

会議还就中国科学院哲学社会科学部各研究所和各省、市、自治区的哲学社会科学 研究所的研究工作規划以及进一步加強这些研究所的問題交換了意見。[新華社稿] 